\title{
The Competition Commission Health Market Inquiry Report: An overview and key imperatives
}

\author{
G C Solanki, ${ }^{1,2,3}$ BChD, BA Hons, MSc, DrPH; J E Cornell, ${ }^{4}$ BA, Perf Dip, MA, DHMEF, PhD; D Besada, ${ }^{1}$ BSc, MPH (Epidemiology and \\ Biostatistics), PG Dip (Health Economics); R L Morar, ${ }^{5}$ MB ChB, DHMEF, MMed (Community Health), FCPHM (SA), CPCP (Coaching); \\ T Wilkinson, ${ }^{6}$ BPharm, MSc (Health Economics) \\ ${ }^{1}$ Health Systems Research Unit, South African Medical Research Council, Cape Town, South Africa \\ ${ }^{2}$ Honorary Research Associate, Health Economics Unit, School of Public Health and Family Medicine, University of Cape Town, South Africa \\ ${ }^{3}$ Principal Consultant, NMG Consultants and Actuaries, Cape Town, South Africa \\ ${ }^{4}$ Director of Institutional Development and Planning (retired), Nelson Mandela School of Public Governance, University of Cape Town, South Africa \\ ${ }^{5}$ Chief Operating Officer, University of Cape Town, South Africa \\ ${ }^{6}$ Health Economics Unit, School of Public Health and Family Medicine, University of Cape Town, South Africa
}

Corresponding author: D Besada (donnela.besada@mrc.ac.za)

\begin{abstract}
The Competition Commission's Health Market Inquiry (HMI) is the most systematic and comprehensive investigation carried out into the South African private health sector. The recommendations as set out in the HMI Final Report merit extensive discussion and debate, as they could - if implemented - have far-reaching consequences for the future of the healthcare system. The objective of this article is to contribute to this discussion by providing an overview of the key findings and recommendations of the HMI and highlighting the resultant key imperatives at this critical juncture of policy development.
\end{abstract}

S Afr Med J 2020;110(2):88-91. https://doi.org/10.7196/SAMJ.2020.v110i2.14455

The South African (SA) private healthcare system is relatively well resourced, with substantially higher per capita spending than the public sector. Private healthcare inflation has been consistently higher than the consumer price index, making cover increasingly unaffordable. ${ }^{[1]}$ In the light of these increases, which only a minority of South Africans can afford, the Competition Commission (CC) initiated the Health Market Inquiry (HMI) in 2013 to investigate and provide explanations for these increases in price and expenditure. ${ }^{[2]}$

Spanning 7 years, the HMI is the most systematic and comprehensive investigation that there has yet been into the SA private healthcare sector. The HMI Final Report, ${ }^{[3]}$ published in September 2019, documents its findings and recommendations in over 250 pages. The recommendations merit extensive discussion and debate, as they could - if implemented - have far-reaching consequences for the future of the healthcare system.

This article is written in the context of significant proposed reform to the SA health system as outlined in the National Health Insurance (NHI) Bill, ${ }^{[4]}$ which will have important implications for the design and regulation of the private healthcare sector. To improve the feasibility and sustainability of NHI, it is imperative that action is taken to address the many issues identified by the HMI in parallel with the incremental NHI implementation process. Well-regulated, efficient, responsive and affordable private voluntary health insurance will be key to achieving universal health coverage (UHC), aligned with the vision of NHI. The collapse of private insurance in SA, a very real risk if the HMI recommendations are not implemented, will only serve to delay UHC, and impede progressive realisation of the right to health for another generation. The objective of this article is to contribute to discussion by providing an overview of the key findings and recommendations of the HMI and highlight the resultant imperatives at this critical juncture of policy development.

\section{Purpose and process}

The HMI was initiated in response to concerns regarding affordability of private healthcare cover in SA. The Terms of Reference published in the Government Gazette on 29 November 2013 stated that the CC wanted the HMI 'to establish whether there are any factors that prevent, distort or restrict competition in the private healthcare sector' and to collect information to 'provide a factual basis upon which the Commission can make evidence-based recommendations that serve to promote competition in the interest of a more affordable, accessible, innovative and good quality private healthcare'.

While Judge Sandile, Chairperson of the HMI panel, acknowledged 'that the crucial issue of equitable and fair access to good quality healthcare services does not rest entirely on competition, ${ }^{3}{ }^{[2]}$ the HMI carried out its investigation primarily through a competitive lens to answer 'whether there are features in the private healthcare markets for services and goods which harm competition or have the potential to harm competition'. Judge Sandile further noted that 'A comprehensive commission of inquiry into the state of healthcare in both the public and private sectors may be more appropriate to evaluate the general state of healthcare services in South Africa in order to give effect to the constitutional right of access to healthcare services and goods guaranteed in section 27 of the Constitution. ${ }^{\text {'[2] }}$

The CC appointed a panel of six experts to conduct the HMI. The establishment phase involved setting up the platform for the inquiry process, and initial engagement with stakeholders. The evidencegathering phase entailed: (i) background research; (ii) more than 15000 pages of written submissions from stakeholders, mainly technical data and information on various healthcare markets; (iii) data from 175 stakeholders (including financial data and detailed claims data for 2010 - 2014 from 80 medical schemes); and (iv) public hearings and seminars on selected topics. The third phase 
entailed analysis of the data and information collected, to determine expenditure and cost trends, profitability and market power. The fourth phase included the publication of the Provisional Report on 5 July $2018^{[5]}$ and an invitation to stakeholders to submit comments. Following review of the comments received, the Final Report was published on 30 September 2019.

\section{Key findings and recommendations}

The focus of the inquiry was the 8.8 million lives (total SA population 53.7 million) covered by private health insurance. The key role players in the healthcare market identified by the HMI were the public health sector, regulatory bodies, medical product suppliers, private healthcare providers (practitioners, facilities, emergency services and pharmacies), private healthcare funders and industry bodies. The HMI focused largely on the interplay between private financers and providers, and the role of regulation and regulatory bodies governing that interaction.

Chapter 3 of the Report sets out the Competitive Assessments Framework, where the HMI assessed the competitive issues related to the private healthcare market. The framework comprised six 'harms to competition' (any effect adverse to the realisation of more competitive outcomes for consumers). These included distortions in relation to: (i) financing; (ii) facilities; (iii) practitioners; (iv) barriers to entry, expansion, intervention and innovation; $(v)$ imperfect information; and ( $v i)$ the regulatory framework.

In effect, the HMI relied on a broad microeconomic assessment framework. For the purposes of this article, we summarise the findings and recommendations within a more generic classic microeconomic framework as set out by Parkin et al. ${ }^{[6]}$ and summarised in Table 1. The framework identifies four key conditions to be met for a market to be competitive: $(i)$ no or limited market concentration, with a large number of buyers and sellers; (ii) free entry into and/ or exit from the market, with no or lower barriers to entry and exit; (iii) 'transparency' with regard to the product being bought/sold in the market - producers should be competing on the price and quality of a fairly homogeneous product; and (iv) perfect consumer information - consumers should be sufficiently informed to make an informed choice when purchasing the product. Although the HMI examined competitive issues at a more granular level, we use this framework to summarise the findings and recommendations broadly for (i) providers of healthcare services (providers), and (ii) funders of healthcare services (funders).

The overall conclusion of the HMI is that the private SA healthcare market suffers from multiple market failures from both provider and funder perspectives, with structural, behavioural and regulatory problems that harm competition and undermine access to healthcare. The HMI ascribes this situation to regulatory failure due to deregulation in the 1980s, followed by partial and incomplete re-regulation and failure to monitor and ensure regulatory compliance.

The provider-side problems and recommendations to address the problems are summarised in Table 1 .

The HMI found that the combination of healthcare practitioners acting as agents for ill-informed individuals requiring healthcare and the perverse incentives associated with the largely fee-for-service remuneration environment facilitated supplier-induced demand; this was the key driver for increases in healthcare utilisation and costs.

The HMI found the healthcare facilities market to be highly concentrated, with three groups (Netcare, Mediclinic and Life) dominating and little evidence of competition between them; this led to the conclusion that the absence of any meaningful recent entry into the facilities market was suggestive of significant entry/exit barriers. The HMI found a lack of transparency in the services provided by facilities and providers, including a lack of price transparency and reporting on quality and outcomes, with non-compliance with protocols and guidelines. It also reported a lack of information and/ or communication from healthcare suppliers and facilities that would allow consumers to make informed choices.

The HMI recognised the need to improve the regulatory environment governing suppliers and recommended the establishment of a dedicated supply-side regulator of health (SSRH)

Table 1. Provider problems and recommendations

\begin{tabular}{lll}
\hline Condition & Problem & Recommendations \\
\hline Market concentration & - Three dominant hospital groups & - Improve regulatory environment by establishing \\
an SSRH responsible for: & - Facility planning, including licensing \\
Free entry/exit & practitioners across specialties & - Conducting economic value assessments of \\
Transparent product & - No meaningful entry in past decade & - Monitoring of health services
\end{tabular}


with four main functions: (i) facility planning (including licensing); (ii) economic value assessments; (iii) monitoring of services; and (iv) pricing. A primary concern is the high level of national and local concentration in the hospital market and the need to implement and update the provisions on the Certificate of Need in the National Health No. 61 of 2003. ${ }^{[7]}$

The funder-side problems and recommendations to address them are summarised in Table 2 .

Overall, the HMI concluded that 'funders compete in an environment which is characterized by an incomplete regulatory framework, so distorting the parameters of competition'. The HMI found the funder market to be highly concentrated, with $70 \%$ of insured lives in two medical schemes (Discovery Health and GEMS (Government Employees Medical Scheme)) and 76\% of insured lives administered by two companies (Discovery Health and Medscheme). The HMI concluded that there was little competition and that funders, together with administrators and managed care companies, had failed to manage supplier-induced demand or moral hazard. Competition between schemes to improve affordability and valuefor-money cover was limited: instead schemes competed based on risk factors, such as attracting healthier members.

The complexity of the offerings by medical schemes (270 products) made it difficult for consumers to compare and make informed choices. Consumer information was incomplete, and the role of brokers and other agents in directing consumer choice was questionable. The HMI further concluded that scheme and member interests were misaligned, with limited incentives to ensure that scheme employees and trustees act in the best interests of members and hold administrators to account.

The HMI funder recommendations 'are designed to complete the regulatory framework, and to create a market environment conducive to effective competition on pro-consumer metrics. While funders were better regulated than suppliers, regulation was incomplete and needed to be improved. Interestingly, while the HMI recognises that mandatory cover would address the problem of anti-selection, it recommends that the 'industry needs to show clear indications of close alignment to consumer interests and better cost containment' before mandatory cover is introduced. To 'remove the current incentive for schemes to compete on low level competitive factors such as attracting a younger population, the HMI recommends the implementation of a risk-adjustment mechanism (RAM) and income cross-subsidisation to mitigate the impacts on scheme costs.
To address the issue of product transparency and homogeneity and consumer information, the HMI recommends the implementation of a standardised package of benefits, explicitly defined and offered by all schemes, with supplementary packages provided in a transparent manner. It further recommends that the standard package be based on revised Prescribed Minimum Benefits (PMB), covering catastrophic expenditure and some level of out-of-hospital and primary care, with a view to encouraging reduced use of higher levels of care. The package should be based on assessments conducted by an SSRH economic value assessment unit using health technology assessment (HTA) and clinical treatment protocols to encourage effectiveness and efficiency. The HMI concludes that establishing an appropriate regulatory framework is necessary to facilitate innovative and alternative models of care that permit interprofessional and interdisciplinary group practice; this would have a positive effect on the provision of care and prevent revenue-maximising behaviour.

A number of recommendations were aimed at enhancing governance, including more stringent reporting requirements, review of reimbursement requirements to better align scheme and member interests, minimum education and training standards for trustees and principal officers, and steps to encourage member participation in trustee election.

\section{Key imperatives}

The findings and recommendations of the HMI are broad and wide ranging, though neither profound nor unexpected, especially from a process that cost at least ZAR196 million and took 7 years to complete. At a broader level, the HMI process and outcomes highlight the need for a review of policy development and co-ordination processes. If government is committed to healthcare for all, would a more comprehensive inquiry into the state of healthcare in both the public and private sectors - as recommended by the chairman of the HMI panel - not have been more appropriate? Alternatively, if government is committed to NHI as the solution to the problems of healthcare, the usefulness of a major enquiry into private healthcare at this time must be questioned.

In any event, the HMI recommendations need to be contextualised within the broader political context of healthcare policy and planning initiatives, especially the government's intention to address the inequities and failings of the two-tiered SA healthcare system through the proposed NHI. Within this context, it makes sense to prioritise the HMI recommendations that not only assist in

Table 2. Funder problems and recommendations

\begin{tabular}{lll}
\hline Condition & Problems & Recommendations \\
\hline Market concentration & - High level of concentration in schemes and & - Introduce single, comprehensive, standardised \\
& administrators & base benefit option \\
& - Lack of competition among funders and & Introduce a risk-adjustment mechanism \\
& - Schinistrators & - Review contracts to ensure move to value-based \\
& - Failure to manage supplier-induced demand, & contracting \\
& moral hazard & Review training requirements and incentives for \\
& - No meaningful entry in past decade & - Introduce an active opt-in system for brokers \\
Free entry/exit & - Multiple product offerings & - Continue with existing CMS functions \\
Transparent product & - Lack of transparency and comparability & - Review PMB \\
Perfect consumer information & - Incomplete information & - Review governance \\
& - Distortions due to brokers and other intermediaries & Improve anti-selection measures
\end{tabular}


improving the current healthcare environment but are also necessary for the successful implementation of NHI.

Taking into account the above, the HMI provider-side recommendations, and in particular the recommendation to establish the SSRH, should be a major implementation priority to address some of the major problems in the current healthcare environment. This is also necessary for the NHI environment; while NHI would have power as a funding body, it would have no regulatory powers and would have to rely on a suitably empowered regulatory body to deal with supplier regulatory issues. There is also a need for a major review of the regulatory environment of the statutory councils that govern health professionals.

The introduction of an economic value assessment unit within the SSRH or as an independent entity is a particularly low-hanging fruit. Through such an entity, the benefit package can be explicitly defined $^{[8]}$ through the inclusion of cost-effective interventions enabled by HTA. The establishment of an economic value assessment unit would ease pressure on the Council for Medical Schemes by alleviating the need to make coverage decisions on a case-by-case basis and contribute to the determination of a revised standardised benefits package, a highly urgent task as the last substantial revision to the PMB was almost 20 years ago. Crucially, this unit could inform and later merge with the HTA and benefits package design process envisioned under NHI. There would be highly useful synergies in a common institution providing economic assessment in both the public and private healthcare sectors, noting critical differences between the decision frameworks underpinning a regulated standard benefits package under a voluntary health insurance mechanism (constrained by criteria such as average premium relative to national household income and scheme viability) and the comprehensive package of benefits under a tax-based UHC mechanism under NHI (constrained by total government health expenditure). Should voluntary health insurance be restricted to supplementary care, following full implementation of NHI (in 2026 at the earliest) the differentiation between a regulated private insurance package and the publicly funded package may become more stark, but both sectors would still require economic assessments to determine efficiency, effectiveness and equity.

A critical concern in the recommendations relating to an economic value assessment unit is the institutional capacity, human resources and research funding required to support economic value assessment of all services within the base benefit package. The HMI correctly determined that the current absence of regulations on HTA is a significant regulatory failure, yet no interim recommendations are made as to how the institutional capacities should be developed. International experience indicates that comprehensive HTA functionality requires dedicated, stepwise strategies related to institutional development and skills and knowledge capacity strengthening. ${ }^{[9]}$ These strategies cannot be limited to NHI processes only and should be funded, developed and implemented urgently.

The case for the HMI funder recommendations is less clear cut. There is currently a need for regulatory coherence between the Council for Medical Schemes and the Health Professions Council of South Africa. The publication of the Medical Schemes Amendment Bill ${ }^{[10]}$ prior to completion of the HMI underlines the question of co-ordination between statutory bodies. While some of the HMI recommendations have been incorporated into the Medical Schemes Amendment Bill, the establishment of the RAM, a key recommendation, was not, and it remains unclear whether it will be adopted.

\section{Conclusions}

The efficiency of the process used for the HMI can be questioned, and the findings are neither profound nor unexpected. However, the recommendations are important and should be acted upon, as they will not only assist in improving the current healthcare environment but are critical for successful implementation of NHI.

\section{Declaration. None.}

Acknowledgements. The authors acknowledge the institutional support of the South African Medical Research Council (SAMRC) and the University of Cape Town provided to the study authors.

Author contributions. Conceived and designed the study: GCS, JEC, RLM, TW. Analysed the data: GCS, JEC, DB, RLM, TW. Developed the article: GCS, JEC, DB, RLM, TW.

Funding. GCS is employed on a contractual basis by the SAMRC and NMG Consultants and Actuaries. Support in the form of salaries was provided by the SAMRC for authors GCS and DB, and by the University of Cape Town for JEC, RLM and TW. None of these institutions had any additional role in the study design, data collection and analysis, decision to publish, or preparation of the manuscript.

Conflicts of interest. GCS is employed on a contractual basis by NMG Consultants and Actuaries, an independent consulting firm providing consulting and actuarial services to SA private health insurance funds. NMG did not have any role in the study design, data collection and analysis, decision to publish, or preparation of the manuscript. As such, there were no conflicts of interest in the conduct of the study.

1. Motsoaledi A. Minister of Health press briefing on NHI Bill. http://www.health.gov.za/index.php/ component/phocadownload/category/383\# (accessed 3 October 2019).

2. National Department of Health, South Africa. Competition Commission of South Africa: Terms of reference for market inquiry into the South African private healthcare sector. Notice 1166 of 2013. Government Gazette No. 37062, 29 November 2013. https://www.gov.za/sites/default/files/gcis Government Gazette No. 37062, 29 November 2013. https://www.gov.Za/sites/default/files/gcis
document/201409/37062gen1166.pdf (accessed 3 October 2019).

3. Competition Commission of South Africa. Health Market Inquiry Final Findings and Recommendations Report. September 2019. Government Gazette No. 42861, 29 November 2019. https://www.gov.za/sites/ default/files/gcis_document/201911/42861gon1533.pdf (accessed 14 January 2020).

4. National Department of Health, South Africa. National Health Insurance Bill. 2019. https://www.gov.za/ sites/default/files/gcis_document/201908/national-health-insurance-bill-b-11-2019.pdf (accessed 4 October 2019).

5. Ngcobo JS. Presentation of HMI Provisional Report. 5 July 2018. http://pmg-assets.s3-website-euwest-1.amazonaws.com/180705Panel-Chair-Former-Chief-Justice-Sandile-Ngcobo.pdf (accessed 3 October 2019).

6. Parkin M. Powell M, Matthews K. Essential Economics. European edition. London: Pearson Education, 2012.

7. National Department of Health, South Africa. National Health Act No. 61 of 2003. Government Gazette No. 26595, 23 July 2004. https://www.up.ac.za/media/shared/12/ZP_Files/health-act.zp122778.pdf (accessed 40 cob 2019).

8. Glassman A, Giedion U, Sakuma Y, Smith PC. Defining a health benefits package: What are the necessary processes? Health Syst Reform 2016;2(1):39-50. http://doi.org/10.1080/23288604.2016.1124171 processes? Health Syst Reform 2016;2(1):39-50. https://doi.org/10.1080/23288604.2016.1124171 9. Culyer A, Podhisita C, Santatiwongchai B. A Star In The East: History of
https://f1000research.com/documents/6-487 (accessed 5 October 2019).

10. National Department of Health, South Africa. Medical Schemes Amendment Bill, 2018. Government Gazette No. 47126, 21 June 2018. http://www.gpwonline.co.za/Gazettes/Gazettes/41726_21-6_Health. pdf (accessed 4 October 2019).

Accepted 12 November 2019. 